\title{
LOS OTROS ROSTROS DE ALF ROSS. IDEAS PARA UN ANÁLISIS CRÍTICO DEL DEMOKRATI, MAGT OG RET, 1974*
}

\author{
THE OTHER FACES OF ALF ROSS. \\ HINTS FOR A CRITICAL ANALYSIS OF \\ DEMOKRATI, MAGT OG RET, 1974
}

\author{
Alessandro Serpe \\ Università degli Studi G. D'Annunzio di Chieti e Pescara
}

Fecha de recepción: 19-2-21

Fecha de aceptación: 30-4-21

Resumen: Alf Ross es conocido como uno de los filósofos del derecho más influyentes del siglo XX. Su pasión más profunda por la teoría del derecho no le impidió explorar hábilmente aspectos claves de la práctica jurídica y contribuir de alguna manera al debate público de su tiempo. Demokrati, magt og ret. Indlæg i dagens debat, de 1974, es un conjunto de artículos de prensa que ofrece un examen en profundidad de complejos problemas jurídicos, políticos y morales. El volumen muestra cómo los principales presupuestos de su realismo le sirvieron de indicios para comprender cuestiones prácticas $y$, lo que es igualmente importante, revela los diferentes rostros del autor y una personalidad multifacética y fascinante.

Abstract: Alf Ross is best known as one of the XX's century most authoritative legalphilosopher. His deepest passion for the theory of law did not refrain him from deftly exploring key-practical aspects of law and contributing in some way to the public debate of his time. Demokrati, magt og ret. Indlæg $i$ dagens debat, 1974, is a collection of articles for newspapers offering a sustained examination of complex legal, political and moral issues. The volume displays how the main tenets of his Realism served him as a clue in understanding practical issues, and, equally importantly, it reveals a fascinatingly polyhedric personality.

* Traducción al castellano de la Dra. Flor María Ávila Hernández y del Dr. Dimitri Endrizzi, Universidad Católica de Colombia.

ISSN: 1133-0937

DERECHOS Y LIBERTADES

DOI: https://doi.org/10.20318/dyl.2022.6514

Número 46, Época II, enero 2022, pp. 65-83 
Palabras clave: democracia, libertad de expresión, poder, derecho. Keywords: democracy, freedom of expression, power, law.

\section{INTRODUCIENDO A ROSS, 1974}

No es inusual que un filósofo del derecho, por las razones más variadas, se sustraiga del debate público y persiga sus intereses e ideales permaneciendo dentro de la fuerte y pura turris eburnea del elitismo académico. Para el danés Alf Ross, fué diferente. Su hambre de ciencia no clausuró entre las paredes de una torre de marfil, sino que entró frecuentemente en la vida cotidiana, individual y colectiva. El volumen Demokrati, magt og ret (Democracia, poder y derecho), de 1974, constituye el más vivo testimonio de su empeño civil, de jurista práctico y comentarista agudo de la sociedad, por cuestiones prácticas de la ciencia política, de la economía y del derecho. En particular, del derecho penal, comparado e internacional. En este volumen, Democracia, poder y derecho, Ross selecciona y vuelve a publicar una serie de ensayos y artículos que habían salido en revistas y periódicos de su país de origen, Dinamarca, en un periodo que iba desde 1957 hasta 1974. El subtítulo, Indlæg i dagens debat (Contribuciones al debate actual) encierra, como en una fórmula matemática, su poner a prueba en la arena pública sus propias doctrinas y convicciones. El volumen está dividido en tres secciones: democracia, poder y derecho. Secciones diferentes entre sí, pero caracterizadas por una sustancial unidad y coherencia. El fil rouge que las une es un conjunto de reflexiones y de ejercicios civiles que se proponen comprender qué es efectivamente y qué debe ser la democracia, a través de los instrumentos de su infatigable fe filosófica: el realismo ${ }^{1}$.

La traducción italiana de este volumen ${ }^{2}$ es complementada, a nivel de apéndice, con dos ensayos significativos y consistentes escritos en años an-

1 En el milieu académico escandinavo, se puede consultar A. ROSS, Demokrati, magt og ret. Indlæg $i$ dagens debat, Lindhardt og Ringhof, Copenhague, 1974, prueba contundente de la recepción crítica del filósofo y jurista noruego Frede Castberg (1893-1977). Castberg fue un incansable partidario de un regreso al derecho natural, dentro de una concepción normativista del derecho, en profundidad para desligarse del realismo filosófico e jurídico de Axel Häagerström y de Alf Ross. Ver F. CASTBERG, “Alf Ross: Demokrati magt og ret, Kobenbavn 1974”, Lov og Rett, 1975, pp. 43-46. Sobre la figura de Frede Castberg (1893-1977) dentro del panorama filosófico-jurídico escandinavo y, en particular, sobre los temas democracia, libertad e igualdad, en comparación con Ross, refiriéndose al mío: A. SERPE, Realismo nordico e diritti umani. Le 'avventure' del realismo nella cultura filosofico-giuridica norvegese, Editoriale Scientifica, Napoli, 2008, pp. 176-183.

2 A. ROSS, Democrazia, potere e diritto. Contributi al dibattito odierno (introducción y traducción de A. SERPE), Giappichelli, Torino, 2016. 
teriores, Kommunismen og Demokratiet (El Comunismo y la Democracia) y Socialismen och Demokratin (El Socialismo y la Democracia) publicados, respectivamente, en danés, en 1945, y en sueco, en 1947, en la revista Tiden ${ }^{3}$. El apéndice refuerza, debido a su perfil teórico y no contingente, el cuerpo de los textos contenidos en el volumen, confirmando, en el fondo, la intención de Ross: reflexionar y llevar a cabo una estrecha comparación entre el liberalismo, el comunismo y el socialismo. El programa es unitario y el espíritu del volumen no es traicionado.

El último escrito del volumen, Credo, parece estar allí para cerrar el cerco. Era el 21 de junio del 1974, pocos años antes de su desaparición. Ross, como en un testamento intelectual, respondía, entre la tranquilidad y quietud de los bosques al norte de Copenhague, a una entrevista para el diario danés Berlingske Aften's kronik. En el texto fluye su credo, sus creencias, junto a las inquietudes y al cansancio de una larga historia de lucha intelectual como jurista teórico y práctico. ¿En qué le cree Ross? “Creer en algo -escribía Ross- es más que un simple 'considerar verdadero' ${ }^{4}$. Y después se preguntaba: “¿Qué es lo que considero o creo que es bueno y grande, aquello que le da sentido a la vida, aquello por lo cual puedo estar dispuesto a apostar en la vida? ¿Cuál es la espina dorsal de mi existencia?" ${ }^{5}$. Este es el núcleo central de sus creencias. A las fugas neuróticas de la razón que desbordan en la fe religiosa, fugas que constituyen la prueba, y a su vez la causa, de un escapar de la carga de la decisión y la responsabilidad, y a cualquier forma de iusnaturalismo Ross responde con la aceptación consciente de un vacío ineludible y la incomprensibilidad absoluta de aquellos "espacios infinitos en los que las nebulosas y las galaxias fluctúan millones de años luz distantes en el transcurso de un tiempo que no tiene principio ni fin" ${ }^{6}$. Una lección, cualquiera que sea la intención de Ross en la publicación de estos escritos, viene de la lectura de ellos: la libertad no se da fuera de la responsabilidad.

Casi como en un 'inventario', Ross explicaba, paradigmáticamente, sus credos: su credo en la democracia, su credo en la ciencia, su credo en la li-

3 A. ROSS, Kommunismen og demokratiet, Fremad, Copenhague, 1945 (trad. italiana de A. SERPE, "Il comunismo e la democrazia", en A. ROSS, Democrazia, potere e diritto, cit., pp. 123-147); A. ROSS, “Socialismen och Demokratin”, Tiden, 39, 7, pp. 392-404 (trad. italiana de A. SERPE, "Il socialismo e la democrazia", en A. ROSS, Democrazia, potere e diritto, cit., pp.149-164).

4 Ibid., p. 114.

5 Ibid., p. 116.

$6 \quad$ A. ROSS, “Mit livstestament”, Berlingske Tidende, 14-5-1978. 
bertad de los individuos, su credo en la responsabilidad, su credo en la virtud del juez ${ }^{7}$. Aguas arriba, su credo en la democracia. Y justo la democracia constituye el eje de la primera de las tres secciones del volumen. Qué se inicia, precisamente, desde ella ${ }^{8}$.

\section{SOBRE LA DEMOCRACIA}

Ya en julio de 1945, después de la liberación de las tropas alemanas, Ross se dejó involucrar en un apasionado activismo teórico concerniente al Estado y a la consistencia de la democracia. Un debate que contó con la participación de académicos refinados como Jørgen Jørgensen (1894-1969), profesor de filosofía en la misma universidad de Ross y destacado exponente del empirismo lógico, y Hal Koch (1904-1963), profesor de Historia de la Iglesia en la Universidad de Copenhague9.

Analicemos algunos aspectos del pensamiento de Jørgen Jørgensen y Hal Koch, autores cuyas ideas sobre la democracia marcaron los pasajes más importantes de las reflexiones de Ross alrededor de la democracia, el liberalismo y el socialismo. Jørgensen distinguía cuatro formas de democracia, teóricamente determinadas -política, social, cultural y económica-formas que, a su manera de ver, manifestaban una exigencia de igualdad, pero no de libertad. La libertad era, para Jørgensen, compatible con la democracia en la medida en que su ejercicio no obstaculizase la plena materialización de otros bienes democráticos fundamentales: en primer lugar, la igualdad

7 Ver también, A. SERPE, "I credo di Alf Ross. Scienza, democrazia, giusitizia nelle pagine del Demokrati, magt og ret", Materiali per una storia della cultura giuridica, núm. 2, 2017, pp. 421-448.

8 Las páginas teóricas de Ross son bastante conocidas. Los artículos de Demokrati, magt og ret muestran algunas otras facetas de Ross como respetado periodista, comentarista social y abogado litigante, asesor jurídico para particulares, así como para el gobierno danés. Ross se desempeñó come Juez del Tribunal Europeo Derechos Humanos (desde 1959 a 1972), ocupó el cargo de Secretario de la Cámara de Comercio (desde 1935 a 1977) y en 1953 participó en la redacción de la Constitución danesa.

9 Varias fueron las revistas que dieron la bienvenida al animado debate de esos años sobre democracia y libertad de expresión: además de Frit Danmark, también Politiken, Bedingske Aftenavis, Frie Ord, Land og Folk, Social-Demokraten. Sobre el debate danés de posguerra sobre el concepto de democracia, ver A. SERPE, "Giù dalla torre d'avorio? Ross difensore della democrazia nel dibattito danese degli anni del dopoguerra", Rivista di Filosofia del diritto, núm. 2. 2017, pp. 293-314; también, A. SERPE, Il pensiero filosofico e giuridico danese. Tra comunità democrazia e diritto, Giappichelli, Torino, 2020, pp. 175-197.

DERECHOS Y LIBERTADES

ISSN: 1133-0937

Número 46, Época II, enero 2022, pp. 65-83

DOI: https://doi.org/10.20318/dyl.2022.6514 
social de los individuos. El comunismo habría garantizado la solución en cuanto al mantenerse de la democracia ${ }^{10}$. Para el teólogo e histórico de la iglesia Hal Koch, con el cual Ross, en 1949, trabajaría una voluminosa antología sobre el concepto de democracia nórdica ${ }^{11}$, la esencia de la democracia estaba en el diálogo (samtalen), origen constitutivo del ser humano. Para Koch, la democracia ya no podía ser considerada solamente una forma política de gobierno fundada sobre la regla del principio de la mayoría, sino que debía entenderse como una forma de vida (livsform) que caracterizaría cualquier relación humana, a incentivarse con formas de aprendizaje y educación popular. Partiendo de los conceptos de respeto, comprensión, diálogo, participación a la vida pública y dentro de una perspectiva que tuviese conjuntamente en cuenta la retórica, la dialéctica y el cristianismo reformista de Grundtvig, Koch contraponía la 'palabra' (democracia) a la 'espada' (dictadura y totalitarismo) ${ }^{12}$.

Vayamos a Ross. Ya en Ordet eller Sværdet? -una de sus primeras contribuciones al concepto de democracia- Ross sostenía una doble imposibilidad. En primer lugar, la imposibilidad de conciliar la democracia política con la democracia económica, social y cultural, en cuanto la democracia no expresaba, en su forma de ver, ninguna exigencia de equiparación y de igualdad, como se exigía, por ejemplo, en una economía planificada. En segundo lugar, la imposibilidad de reducir el concepto de democracia a una mera forma de vida. Para Ross, el diálogo satisface las condiciones requeridas por una democracia, pero la democracia es, antes que nada, un procedimiento que presupone el compartir de una ideología. Una tripartición de los significados del concepto de democracia aparece en la breve monografía

10 J. JØRGENSEN, “Demokratiet har Ret til at forsvare sig”, en S. HEIN RASMUSSEN y N. KAYSER NIELSEN (eds), Strid om demokratiet. Artikler fra en dansk debat 1945-46, Aarhus Universitetsforlag, Aarhus, 2003, pp. 20-23.

11 H. KOCH y A. ROSS (eds), Nordisk Demokrati, Westermann, Copenhague, 1949.

12 Nikolai Frederik Severin Grundtvig (1783-1872) fue teólogo, filólogo, político y reformador danés que vivió a lo largo de los años del desarrollo moderno de la sociedad danesa. Ver A. SERPE, “Forme di vita e religione nel luteranesimo riformista del teologo danese Hal Koch. Dalla coscienza del popolo alla democrazia", Diritto e religioni, núm. 1, 2017, pp. 477488; también A. SERPE, Il pensiero filosofico e giuridico danese. Tra comunità democrazia e diritto, cit., pp. 61-85. Sobre Koch y su concepción de democracia como forma de vida: H. KOCH, "Loke og Thor" en S. HEIN RASMUSSEN y N. KAYSER NIELSEN (eds), Strid om demokratiet. Artikler fra en dansk debat 1945-46, cit., pp. 188-207; H. KOCH, “Ordet eller Sværdet” en Ibid., pp. 65-75; H. KOCH, “Ungdomsopdragelsen” en H. KOCH y A. ROSS, Nordisk Demokrati, cit., pp. 395-406; H. KOCH, Hvad er demokrati?, Gyldendal, Copenhague, 1991. 
de 1945, Kommunismen og Demokratiet, contenida, como se anticipó previamente, en un apéndice a la traducción italiana Democrazia, potere e diritto. En el mencionado trabajo, Ross, con el fin de suministrar respuestas adecuadas respectivamente acerca de la posibilidad de desarrollo del comunismo y del socialismo en Dinamarca y de la democracia en la Unión Soviética, consideraba necesario aclarar el opaco e intencionalmente distorsionado mal uso de la palabra 'democracia'. En la tripartición de significados relativos a la democracia planteada por Ross -democracia política (como forma de gobierno), democracia humana (como forma de vita), democracia económica (como forma de economía planificada) - se puede notar de forma clara la influencia de Jørgensen y Koch ${ }^{13}$. Para Ross, 'democracia' es y debe ser un concepto formal y jurídico que denota el cómo y no el qué: la democracia es un método procedimental fundamentado sobre los principios de representación (repræsentationsprinsippet) y mayoría (flertalsprincippet $)^{14}$.

Ross aclara las declinaciones del significado atribuido al concepto de democracia, llegando a la conclusión de que se trata de un método para la resolución pacífica de conflictos. La democracia es, antes que nada, un procedimiento que, para poder funcionar, debe presuponer una ideología ${ }^{15}$. Para Ross, la democracia es, y no puede no ser, "una forma de gobierno; es decir, una forma de organización política, un método político" ${ }^{16}$. Un procedimiento que, gracias al derecho, crea unos límites a las acciones de aquellos que

13 A. ROSS, Democrazia, potere e diritto, cit., p. 130.

14 Ver también: A. ROSS, Hvorfor Demokrati? (1946), Tiden Norsk Forlag, Oslo, 1969, pp. 95-107; A. SERPE, "Su democrazia libertà eguaglianza. À proposito del Ross di Hvorfor Demokrati?", i-lex, num. 20, 2013, pp. 453-478.

15 A. ROSS, "Ordet eller Sværdet?" en S. HEIN RASMUSSEN y N. KAYSER NIELSEN (eds), Strid om demokratiet. Artikler fra en dansk debat 1945-46, cit., p. 161. Sobre su concepción de democracia: A. ROSS, Hvorfor Demokrati?, Nyt Nordisk forlag, Copenhague 1946 (traducción en engles: Why Democracy?, Harvard University Press, Cambridge, Massachusetts, 1952); H. KOCH y A. ROSS (eds), Nordisk Demokrati, cit. (la colección fue traducida, en parte, al inglés: J.A. LAUWERYS (ed), Scandinavian Democracy. Developments of Democratic Thought $\mathcal{E}$ Institutions in Denmark, Norway and Sweden: The Danish Institute, The American Institute, The Norwegian Office of Cultural Relations, The Swedish Institute, The American-Scandinavian Foundation, Copenhague 1958). Vale la pena señalar que esta traducción fue movida por la necesidad de Ross de proponer, en los años difíciles y agotadores de las democracias de posguerra, una idea distintiva común y generalizada de la democracia escandinava, la democracia nórdica. Sobre el concepto de democracia nordica, cfr. A. SERPE, "Giù dalla torre d'avorio? Ross difensore della democrazia nel dibattito danese degli anni del dopoguerra", cit., pp. 297-302.

16 A. ROSS, Why Democracy?, cit., p. 91.

DERECHOS Y LIBERTADES

ISSN: 1133-0937

Número 46, Época II, enero 2022, pp. 65-83

DOI: https://doi.org/10.20318/dyl.2022.6514 
ejercen el poder político. La forma adecuada de democracia se fundamenta en la idea de legitimación y representación. Por supuesto, el pueblo es el titular de la soberanía, pero lo que resulta decisivo es el mandato. Se puede afirmar que un Estado es democrático sólo en la medida en que el poder pertenece al pueblo. Sin embargo, la unidad de medida de una democracia está en el grado real de influencia del pueblo en el ejercicio del poder por parte de las autoridades públicas. Ross señaló las diversas e interactuantes formas en que se materializa la influencia del pueblo: intensidad (intensitet), en términos de acceso de los participantes al electorado activo y pasivo; efectividad (effektivitet), en relación con el grado de posibilidad otorgado al pueblo para afirmar sus propios puntos de vista; amplitud (ekstensitet), con respecto a la medida en que la influencia popular adquiere modos de control sobre los poderes públicos ${ }^{17}$.

Una digresión es necesaria. Para Ross, el modelo y las instituciones de la democracia formal no son incompatibles con los ideales y las instancias del socialismo. No es una coincidencia que Ross le hiciese ojitos, ya en la primera posguerra, a los socialdemócratas y a su programa de reforma económica Fremtidens Danmark, presentado en el Congreso del partido en agosto de 1945. Programa que, en opinión de Ross, presentaba altos niveles de 'racionalidad' tanto en el uso de recursos como de los medios de producción. En lugar de una alternativa dicotómica entre iniciativa privada y economía planificada, Ross vio, más bien, una posibilidad de armonización entre ellas: en el marco de las instituciones de la tradición democrática y liberal, una forma de control público sobre las empresas privadas, pero no entendido como un socialismo de Estado o una centralización burocrática. "Aquel del partido socialdemócrata -declaró Ross, acercándose las elecciones danesas, en un artículo publicado en un periódico sueco de orientación socialdemócrata- es un programa amplio y constructivo que, sin estar atado a una ortodoxia marxista anticuada, se alinea con la ciencia económica más moderna"18. Libertad e igualdad, los grandes valores de la humanidad, contra los temores y dramatizaciones de cada una de las partes, comunistas y capitalistas, en el modelo socialdemócrata de Ross se estarían integrando recíprocamente sin aniquilarse ${ }^{19}$. Para Ross, el futuro de la democracia se encuentra en la

\footnotetext{
17 Ibid., pp. 194, 199, 200.

18 A. ROSS, "Hvorfor jeg stemmer paa Socialdemokratiet", Social-Demokraten, 25-10-1945.

19 Algunas influencias intelectuales son evidentes en el pensamiento de Ross: Hans Kelsen (ideal de la pureza de la ciencia), Max Weber (la objektividad wertfrei; Axel Hägerström
} 
apertura del liberalismo al socialismo. Quien lea sus ensayos, El Comunismo y la Democracia y El Socialismo y la Democracia no podrá no acordarse de estas ideas. "El objetivo -escribía Ross en la parte final de un ensayo de 1945- no es intercambiar nuestra democracia política con un socialismo económico, sino unificarlos. El objetivo del programa contenido en el manifiesto socialdemócrata Fremtidens Danmark es concretar una emancipación económica sin perder los valores culturales fundamentales de la libertad política que hemos heredado. El socialismo conectado con la democracia es la finalidad. La democracia social es el camino" ${ }^{20}$.

$\mathrm{Y}$, finalmente, una última advertencia: Socialismo, sí, pero no en las formas que -como se verá más adelante- se desviarán de sí mismas y se materializarán en hechos como la politización de las universidades y el 'contrabando' de opiniones políticas disfrazadas de 'ciencia'. Realidades contra las cuales el Ross maduro de los años Sesenta elevará fuertes críticas.

\section{DEMOCRACIA Y LIBERTAD DE EXPRESIÓN}

El liberalismo democrático, la democracia representativa y la libertad de expresión son los puntos focales en torno a los cuales se desarrolla el discurso de Ross en los artículos del volumen de 1974. Antes que todo, el liberalismo de John Stuart Mill contra la filosofía de Jean Jacques Rousseau fundada en su creencia en el genio original del pueblo, y, también, contra la 'prueba' utilitarista benthamiana de la absoluta infalibilidad de la democracia ${ }^{21}$. En otras palabras, Ross reivindica la especificidad de los ideales de salvaguarda y protección de las libertades individuales, ideales que se pueden concretar con y a través de la democracia. Democracia como participación directa o

(nihilismo teórico); Herbert Tingsten (concepción de democracia como overideologi), Myrdal (projecto de ingeniería social). Ver, en particular: H. TINGSTEN, "Nordisk Demokrati", Nordens Kalendar, 1938, pp. 41-50; H. TINGSTEN, Demokratiens problem, Norstedts, Stockholm, 1945; G. MYRDAL, An American Dilemma - the Negro problem and Modem Democracy, Harper \& Brothers, New York, 1944; J. STRANG, "Overcoming the rift between 'is' and 'ought'. Gunnar Myrdal and the philosophy of social engineering", Ideas in History, vol. 2, pp. 148-158, 165-168. Sobre las convergencias y divergencias entre el pensamiento de Ross y Weber, cfr. A. SERPE, "Dardi di fuoco contro la sociologia del diritto. Geiger, Aubert e Goldschmidt nel mirino di Alf Ross", Sociologia del diritto, núm. 2, 2019, pp. 36-38.

20 A. ROSS, Il comunismo e la democrazia, cit., p. 147.

21 A. ROSS, Why Democracy?, cit., pp. 41-74. Ver también, A. ROSS, "Il romanticismo politico del nostro tempo" en A. ROSS, Democrazia, potere e diritto, cit., pp. 23-27.

DERECHOS Y LIBERTADES

ISSN: 1133-0937

Número 46, Época II, enero 2022, pp. 65-83

DOI: https://doi.org/10.20318/dyl.2022.6514 
indirecta del pueblo en la vida política. El núcleo de los derechos de libertad, los derechos civiles, constituyen para Ross la primera condición; ellos, a su vez, encuentran ulterior fuerza en los derechos políticos, complementándose y sosteniéndose entre sí. La democracia es, para el danés (como para Kelsen) procedimiento, método político, forma de gobierno. Sin embargo, estos elementos no son sino el requisito previo para un liberalismo social completo ${ }^{22}$.

Para Ross, hablar de los ideales de autodeterminación y autonomía no significa estar hablando de democracia directa. Estos supuestos, casi el corazón de su reflexión sobre la democracia, siguen siendo significativamente fuertes y se afirman, en los mencionados ensayos, de manera ejemplar. En los años de revueltas estudiantiles en la Universidad de Copenhague, Ross se encargó de mostrar la falsa moralidad y la nociva infidelidad de las denominadas corrientes revolucionarias que, especulando sobre el concepto de democracia, lograron ser consideradas como actores del cambio social. "Existen dos ideologías entre ellas radicalmente diferentes. Según la primera -escribía Ross, a propósito de las revueltas estudiantiles de los fines de los años Sesenta- recurrir a la representación es solo uno de los instrumentos técnicos a utilizar en algunas circunstancias específicas. Como principio general, es deseable que el pueblo tome decisiones directamente (...). Se trata en este caso de democracia directa. Con base en la segunda concepción, la representación es, al contrario, deseable en sí. El oficio del pueblo se concreta solamente en escoger sus propios representantes, no en tomar decisiones políticas. El pueblo es el órgano que nombra, no el órgano que decide. Bajo esta perspectiva, se materializa la democracia puramente representativa" ${ }^{23}$.

Para el liberal Ross, el ideal de la autodeterminación, en el cual tiene sus raíces el modelo de la democracia directa, no es incompatible con aquel de la democracia representativa. De hecho, la autodeterminación debe unirse al "reconocimiento del rol del liderazgo y la necesidad de competencias en la vida política" ${ }^{24}$. Con respecto a la Universidad, Ross concluía: "La competencia que se requiere para administrar una universidad -por ejemplo, para tomar decisiones sobre la organización de los exámenes, sobre el contenido de los estudios, sobre el nombramiento de profesores, sobre la asignación de títulos, etc.- es la misma que posee el personal docente, especialmente los

22 H. KELSEN, La democrazia, Il Mulino, Bologna, 1998, pp. 191-199.

23 A. ROSS, "Il romanticismo politico del nostro tempo: la democrazia diretta" en A. ROSS, Democrazia, potere e diritto, cit., p. 24.

24 Ibid., p. 25. 
más altamente calificados" 25 . Una exaltación del uso de la democracia constituía la razón infundada de la atribución del gobierno de las universidades a un personal diferente al de los funcionarios puramente técnicos, académicos y administrativos.

Democracia representativa y libertad de expresión caminan mano a mano en las reflexiones de Ross. En muchas de sus páginas, el autor plantea, casi como un imperativo, la necesidad de una libertad de expresión sin restricciones. A principio de la década de 1960, Ross se interrogaba: “ ¿Estamos dispuestos, para la defensa de la democracia -en su núcleo de derechos democráticos de libertad, la libertad de expresión y, con ella, la libertad de religión, de asociación, de reunión- a limitar, y también a prohibir, actos contrarios a la democracia, inclusive la sola propaganda antidemocrática y la conformación de partidos antidemocrático?" 26. Y también: "Podemos cerrar la boca a la gente -leemos en las páginas de un ensayo de los años Sesentapero no mantener amarrados sus pensamientos. Aquellos que quieren defender a los pueblos de la propaganda antidemocrática son como Odiseo, que tapó las orejas de sus marineros con cera de modo tal que no pudieran escuchar ni dejarse atrapar por el canto peligroso de las Sirenas. No creo que, en este modo, se pueda hacer eterna la democracia" ${ }^{27}$. Sin embargo, para Ross, la libertad de expresión no significa apertura a toda forma de manifestación: es legítimo pensar en una restricción de libertad de expresión, si en su ejercicio comprendiera evocación e incitación a la violencia ${ }^{28}$.

Estas adquisiciones teóricas de finales de los años cuarenta encontraron vitalidad y confirmación en los años difíciles de las protestas juveniles y las revoluciones anticapitalistas que se materializaron, a los ojos de Ross, como expresiones de formas violentas de cultura y acción. Propaganda inculcada, plazas llenas de gente, estruendo. Así se dio una cultura de la violencia en la opulenta sociedad de finales de los años sesenta. La teoría social de Marcuse, un pensador de la escuela de Frankfurt muy popular en esa época, se convirtió, aterradoramente, en el vademécum de los revolucionarios, un remanente indigesto del hegelianismo "absolutamente incompatible -en palabras de

25 A. ROSS, "Democrazia e amministrazione delle università" en A. ROSS, Democrazia, potere e diritto, cit., p. 35.

26 A. ROSS, "Libertà - anche per i nemici della libertà?", en A. ROSS, Democrazia, potere e diritto, cit., pp. 17-22.

$27 \quad$ Ibid., pp. 20, 21.

28 Sobre esto punto ver también: A. ROSS, Why Democracy?, cit., pp. 234-236.

DERECHOS Y LIBERTADES

ISSN: 1133-0937

Número 46, Época II, enero 2022, pp. 65-83

DOI: https://doi.org/10.20318/dyl.2022.6514 
Ross- con la ciencia empírica moderna y la filosofía crítica" 29. 'Liberación', 'gente', 'conciencia', 'verdad', 'adoctrinamiento' son los términos con los que Marcuse, para Ross, mostró su verdadera intención: subvertir el sistema político y legal, y también disolver la moral social. En opinión de Ross, la libertad no admite violencia. Para aquellos que profesan una conciencia profundamente democrática se vuelve fundamental rechazar cualquier forma de incitación al uso de la violencia y otros métodos ilegales.

Las suposiciones de Ross son las mismas a lo largo de los años: la democracia, si es auténtica democracia, conlleva también la cura para sus dolencias. Como es evidente, los argumentos de Ross presentes en los ensayos aquí recopilados no difieren de aquellos que caracterizaron los años de la posguerra. Ciertamente años diferentes. Sin embargo, los argumentos de Ross dejaban entrever el mismo espíritu: la fe en la democracia y en la libertad de expresión.

\section{DEMOCRACIA Y PODER}

La segunda parte de Demokrati, magt og ret recoge sus artículos sobre el tema del poder en la política internacional y presenta una elevada coherencia respecto al espíritu de los artículos contenidos en la primera parte. Estos artículos de Ross mantienen firme, en las formas que se verán, dominio jurídico y dominio político, aclarando, cada vez, la intrínseca defensa del derecho a partir del poder. En consecuencia, Ross no cierra la brecha entre la ley y la política y muestra, en las tramas de su escenario histórico contemporáneo, el recíproco juego de espejos.

Ross ocupó la cátedra de Derecho internacional en la Universidad de Copenhague desde 1938. Ya en la mitad de los años cuarenta, Ross había construido un sistema teórico de cierta consistencia. Sus reflexiones sobre la democracia mal se entenderían si no se tomasen en cuenta dentro del marco de una conciencia ya extendida, abierta gracias a su desencantado realismo. Analicemos el tema más de cerca.

Towards a Realistic Jurisprudence. A Criticism of the Dualism in Law es de 1946.

El volumen retornaba a su precedente trabajo del 1934, que había sido destinado a un público escandinavo, con el título de Virkelighed og gyldighed

29 A. ROSS, “Allora leggete il Marcuse!”, en A. ROSS, Democrazia, potere e diritto, cit., p. 3. 
i retslæren ${ }^{30}$. Esta obra marcaba, por un lado, la distancia de Ross del maestro Hans Kelsen y, por el otro lado, mostraba una evidente inspiración en la filosofía antimetafísica de Axel Hägerström. Quizás demasiado evidente fue la inspiración: el escrito Kritik der sogennanten praktischen Erkenntnis, de 1933, había sido acusado de plagio por parte del discípulo sueco de Hägerström, el filósofo Anders Wedberg (1913-1978) ${ }^{31}$. De hecho, Virkelighed og gyldighed deja entrever una profunda influencia de la filosofía de Hägerström: la filosofía antimetafísica de los fenómenos morales y jurídicos. La idea de que las expresiones de deber y de valor no son sino expresiones sin algún significado lógico constituyó la inspiración teórica decisiva para el 'nuevo' Ross.

Ross tradujo al inglés gran parte de su trabajo de 1934: Towards a realistic jurisprudence es, como se anticipó, de 1946. El intento de Ross fue el de reconstruir, después de los eventos bélicos, un puente científico entre el contexto escandinavo y el contexto americano, ambos caracterizados, desde su punto de vista, por la misma tendencia hacia una concepción realista del derecho y de los fenómenos jurídicos. Del mismo año de Towards a Realistic Jurisprudence, -caracterizada por una crítica a la ontología de los conceptos jurídicos- es su primera monografía sobre el derecho internacional, Lærebog $i$ Folkret. Almindelig Del (Manual de Derecho Internacional. Parte general). Si Ross, por un lado, es consciente del hecho de que la literatura en lengua inglesa abundaba en tratados sobre Derecho internacional, por el otro, tenía clara la originalidad de su trabajo. Las visiones del Derecho allí contenidas y la consiguiente doctrina de los roles de la jurisprudencia desde una perspectiva escandinava, en su opinión, no tenían precedentes similares en la literatura angloamericana ${ }^{32}$. El manual, escrito unos años después de obtener la cátedra de Derecho Internacional en la Universidad de Copenhague, será traducido, solo un año después, al inglés con el título A Textbook of International Law. General Part.

30 Virkelighed og Gyldighed $i$ Retslæren. En Kritik af den teoretiske Retsvidenskabs Grundbegreber, Levin \& Munksgaard, Copenhague, 1934 fue publicado cinco años después del debatido Theorie der Rechstquellen. Ein Beitrag zur Theorie des positiven Rechts auf Grundlage dogmenhistorischer Untersuchungen, Vorlag Franz Deuticke, Leipzig y Viena, 1929, trabajo en el cual Ross, desde su prefacio, sin ocultar sus deudas con Hans Kelsen, y de sólo un año posterior al igualmente conocido Kritik der sogenannten praktiscben Erkenntnis. Zugleich Prolegomena zu einer Kritik der Rechtswissenschaft, Munksgaard, Copenhague-Menier, Leipzig, 1933, volumen, este último, dedicado, como es conocido, al maestro Axel Hägerström. 114-117.

31 J. EVALD, Alf ross et liv, Jurist og Økonomforbundets Forlag, Copenhague, 2010, pp.

32 A. ROSS, A Textbook of International Law. General part, Longmans, London, 1947, preface.

DERECHOS Y LIBERTADES

ISSN: 1133-0937

Número 46, Época II, enero 2022, pp. 65-83

DOI: https://doi.org/10.20318/dyl.2022.6514 
Towards a Realistic Jurisprudence y A Textbook of International Law presentan una fuerte continuidad conceptual, ambos comparando teoría y práctica. Voy a señalar, nada más que a través de pocos renglones, algunas de las implicaciones filosóficas de A Textbook, con el fin de sentar los grandes lineamientos de los ensayos de la segunda parte de este libro. Según las instancias teóricas de Towards a Realistic Jurisprudence y en los modos de un proceso de 'desracionalización' no existe ningún 'mundo' de normatividad objetiva ${ }^{33}$. Para el Ross de Virkelighed og gyldighed, la validez ("Sollen" eller "Gyldighed") no es un concepto o una categoría, ni, tanto menos, un hecho exterior, un comportamiento. La validez es un 'no sentido', si se entiende o se comprende como categoría conceptual, o cual esfera de la existencia coordinada con la realidad. Para Ross, la validez "pertenece a las racionalizaciones (Rationaliseringer) y a las construcciones (Konstuktioner) y es generada por las experiencias del deber recubiertas por una ilusión de objetividad (Objektivitetsillusion)" ${ }^{34}$. Ross proponía un análisis psicológico según el cual por 'validez' había que entenderse la expresión conceptualmente racionalizada de algunas experiencias subjetivas de impulsos (forestillingsmæssigt rationaliserede Udtryk for visse Subjektive Oplevelser af Impuls $)^{35}$.

En los modos de un proceso de 'deracionalizante disolución conceptual', Ross remplazaba el obsoleto término de tradición iuspositivista-estatalista 'validez' (Gyldighed), categoría radicalmente discrepante de la realidad, con aquel de 'experiencia de validez' (Gyldighedsoplevelser); es decir, de experiencias subyacentes al proceso de racionalización. Para Ross, no se da en el mundo espacio-temporal alguna 'cosa' que sea 'validez', ni algún 'mundo' de normatividad objetiva: se dan, más bien, expresiones conceptualmente racionalizadas de determinadas experiencias subjetivas de impulsos. Reemplazando el término 'validez' con la expresión 'experiencia de validez', Ross terminaba sosteniendo que un sistema jurídico puede ser considerado 'ordenamiento social' si, y solo si, estuviese fundado sobre tres impulsos peculiares: las actitudes de comportamientos desinteresados (uinteresserete Adfardsindstillinger), inducidas por la fuerza de la sugestión social; las acti-

33 Ibid., pp. 91, 96-101. Sobre este punto ver también: A. ROSS, "Retskilde og metodelære i realistisk belysning", Tidsskrift for Rettsvitenskap, 1931, pp. 241-301, especialmente p. 295.

34 A. ROSS, Virkelighed og gyldighed i retslæren, cit., p. 72; véase también, A. ROSS, Towards a realistic jurisprudence. A Criticism of the Dualism in Law, Munksgaard, Copenhague, 1946, p. 48.

35 A. ROSS, Virkelighed og gyldighed $i$ retslæren, cit., p. 91; véase también, A. ROSS, Towards a realistic jurisprudence, cit., p. 77.

ISSN: 1133-0937

DOI: https://doi.org/10.20318/dyl.2022.6514
DERECHOS Y LIBERTADES

Número 46, Época II, enero 2022, pp. 65-83 
tudes de comportamientos interesados (interesserete Adfxrdsindstillinger), inducidas por el temor de la sanción; la interplay, una real interacción inductiva (induktorisk Vekselvirkning) de los dos elementos; es decir, la creencia en la idea práctica de 'validez autoritativa', fundada sobre impulsos desinteresados para actuar, generados por la sugestión social (elemento de validez) y por el temor a la sanción (elemento de la realidad) ${ }^{36}$.

Las adquisiciones de Towards a Realistic Jurisprudence se vierten en cascada en cuanto a los conceptos de 'fuerza vinculante del derecho internacional' y 'fuentes del derecho internacional', y no menos en cuanto al binomio 'derechos-deberes'. Basándose en el mecanismo algo incomprensible de los motivos de la acción, el concepto de 'fuerza vinculante' no podrá decirse fundado ni en la voluntad de la persona sobre quien descansa la obligación, ni en ideas y postulados objetivos; sino que será, ella también, simplemente, un fenómeno sociopsicológico ${ }^{37}$. Estas serán argumentaciones de acuerdo con las cuales la soberanía, o mejor dicho nuestra soberanía, ha sido hecha pedazos por Ross.

Llegamos a los ensayos presentados aquí. El horizonte de las reflexiones de Ross sobre el derecho internacional es un espacio bipolarizado en torno a las dos grandes superpotencias de la época, Estados Unidos y la Unión Soviética, caracterizado por una división persistente entre Occidente y Oriente, alimentada por la presencia de mini-Estados capaces de impedir que la Organización de las Naciones Unidas desempeñe su cargo de garante de la paz en el mundo. La Asamblea General de las Naciones Unidas es tomada como rehén por los mini-Estados: “Después de que la Asamblea General fue inundada -escribió Ross ferozmente- por Estados liliputienses, subdesarrollados, no autónomos e impotentes en su propia casa, pero tan codiciosos para arreglar los asuntos del mundo, esta perdió el derecho a ser considerada la expresión de la opinión mundial. La Asamblea General se ha convertido en la sede de una propaganda llamada 'anticolonial' y 'antiimperialista', y esto en realidad significa propaganda antioccidental, con la cual los estados comunistas, con ingenio, han explotado el odio de los países en vía de desarrollo hacia las antiguas potencias coloniales" ${ }^{38}$. Para Ross, la liquidación del antiguo sistema colonial generó un desconocimiento de las

$36 \quad$ Ibid., p. 92. véase también, A. ROSS, Towards a realistic jurisprudence, cit., p. 78 (disinterested behaviour attitudes; interested behaviour attitudes; interplay).

37 A. ROSS, A Textbook of International Law, cit., pp. 46-49.

38 A. ROSS, "La Danimarca deve vietare la propaganda di guerra?", en A. ROSS, Democrazia, potere e diritto, cit., p. 83.

DERECHOS Y LIBERTADES

ISSN: 1133-0937

Número 46, Época II, enero 2022, pp. 65-83

DOI: https://doi.org/10.20318/dyl.2022.6514 
grandes potencias, beneficiando la vanidad, como un fin en sí mismo, de soberanías insignificantes. La inundación de estados pequeños dentro de las Naciones Unidas, en términos de derecho, su paridad de igualdad jurídica del derecho a la cooperación, no pudo que haber generado un estancamiento significativo del derecho internacional. La intrincada cuestión de la aplicación del Capítulo VII en el caso Rodesia del Sur, en las reflexiones de Ross, no solo evidencia un probable abuso de la Carta, a raíz del control numérico de la Asamblea General por parte de los países en desarrollo, sino también de un alzamiento de una fuerza ideológica que es explotada sistemáticamente por la política en detrimento de la fuerza física jurídicamente legitimada ${ }^{39}$. Las operaciones en Corea, en Gaza, en el Congo, exhibían para Ross la cara de un fracaso de la política de seguridad internacional ${ }^{40}$.

Dicho eso, también en referencia a las decisiones de la Corte Internacional, la falta de una autoridad internacional hace que no sea posible garantizar el cumplimiento de sus decisiones. Ross denunciaba con fuerza la actitud de Islandia -totalmente extraña al espíritu de observancia del poder judicial por parte de los países nórdicos- de deliberada no conformidad a la sentencia emanada de la Corte, relativa al caso de la extensión de las aguas territoriales marítimas islandesas, en perjuicio de Inglaterra. Según Ross, la actitud de Islandia a la Corte es todo menos que derecho, es una burla a los grandes Estados sin encontrar ninguna resistencia, y el falso moralismo con respecto al desempleo de la fuerza es también un síntoma de una política internacional fallida. “No existe -así Ross escribía con crudo realismo- ninguna autoridad internacional con el poder de garantizar que las decisiones de la Corte sean observadas. Y visto que el empleo de la fuerza (...) es condenado, un pequeño estado como Islandia puede insultar a la Corte sin correr riesgos y reírles en la cara a los grandes estados" ${ }^{41}$.

El mantenimiento de la paz, lo que Ross asume y defiende enérgicamente, está, en el fondo, confiado a una red de acuerdos bilaterales que conciernen disjuntamente a las dos superpotencias, Estados Unidos y Unión Soviética. Y no es muy difícil entender hacia cuál de las dos superpotencias se orientó el apoyo de Ross. Frente a una indignada y moralista opinión pú-

39 A. ROSS, "L'abuso della Carta dell'ONU”, en A. ROSS, Democrazia, potere e diritto, cit., pp. 71-77.

40 A. ROSS, “Le Nazioni Unite”, en A. ROSS, Democrazia, potere e diritto, cit., p. 68.

41 A. ROSS, "L'oltraggio dell'Islanda alla Corte", en A. ROSS, Democrazia, potere e diritto, cit., p. 92. 
blica que condenaba la intervención de los Estados Unidos en Vietnam, Ross, sin ambigüedad ni incertezas, se declaró a favor de los americanos, 'culpables' de combatir una guerra para "defender -con palabras de Ross- los valores que son también los nuestros, contra un peligro que nos amenaza también a nosotros" ${ }^{42}$. Posición por cierto incómoda y difícil en aquellos años.

\section{DEMOCRACIA Y DERECHO}

La tercera y última parte del libro en cuestión se compone de un par de ensayos que unen, en la más plena conciencia de sus implicaciones filosóficas, la libertad de expresión y las funciones propias del derecho penal en una democracia liberal y social. La lección liberal de Mill emerge una vez más, enriquecida por las reflexiones de Herbert Hart sobre la relación entre derecho y moral, en particular con respecto a las disposiciones penales sobre el pudor y la publicación de escritos obscenos y más ampliamente entre liberalización y enforcement de la moral en la sociedad. Es fácil entender cómo la posición de Ross se situó, junto a Hart, contra el moralismo legal y, más en general, contra las tareas del derecho dentro de una sociedad en fuerte transformación.

¿Se puede sostener la moral dentro de una sociedad a través del instrumento del derecho? En el fondo, estaba el debate sobre las relaciones entre moral y derecho, que se había desarrollado en Inglaterra entre los años cincuenta y sesenta del siglo pasado: la nota de la Comisión inglesa Wolfenden había sido tenida en cuenta con el fin de expedir un informe sobre la criminalización de la prostitución y de la homosexualidad. En los escritos que componen la tercera parte del volumen de 1974, Ross retomaba la cuestión y se interrogaba sobre la punibilidad o menos de aquellos comportamientos que una parte de la sociedad, grande o pequeña que fuese, consideraba inmorales, aunque no hiciesen daños a terceros. ¿Es realmente necesario castigar tales comportamientos con el fin de mantener un supuesto orden público y las fundamentales existencias de un recíproco respeto para salvaguardar - para decirlo con palabras del distinguido estudioso del derecho penal y miembro de la Cámara de los Lores, Lord Devlin- la sociedad del peligro de desintegración ${ }^{43}$. Ross se mostraba también dispuesto a formas

42 A. ROSS, "Corea, Vietnam e l'anti-americanismo", en A. ROSS, Democrazia, potere e diritto, cit. p. 97.

43 Ver P. DEVLIN, The enforcement of Morals, Oxford University Press, Oxford, 1965.

DERECHOS Y LIBERTADES

ISSN: 1133-0937

Número 46, Época II, enero 2022, pp. 65-83

DOI: https://doi.org/10.20318/dyl.2022.6514 
de represión penal, pero sólo en los casos en que fuese posible 'medir' la cantidad de mal provocado por actos entre homosexuales. No existe, para Ross, así como para Hart del Law, liberty and morality, de 1963, una moral absoluta a la cual el conocimiento práctico, mediante la razón, tenga acceso. Para responder a la pregunta, Ross, aunque partiendo del concepto de Mill de 'daño indebido', iba más allá: el 'daño indebido' no ofrece por sí mismo un criterio exclusivo para una aplicación unívoca. Es absolutamente posible que un cierto tipo de comportamiento pueda ofender los sentimientos de los demás. Entonces, la virtud del juez -y de aquí emerge el significado profundo de su realismo- deberá intervenir balanceando consideraciones prácticas y juicios de valor para ofrecer el argumento conclusivo. El liberalismo de Ross se fundamentaba, así, en la necesidad de librar la realidad de las incrustaciones de los prejuicios generados por la intolerancia religiosa y la intransigencia de la moral. Cuánto sarcasmo en las palabras con las cuales Ross se burlaba de las dificultades en las cuales el famoso estudioso Carriò estaba atrapado cuando, durante el trabajo de traducción al castellano de Law and Justice, se tropezó con la expresión: "Like a harlot, natural law is at the disposal of everyone"! "Hay que reír o llorar? Escojamos reír -así Ross se respondía a sí mismo- porque me parece liberador. Conocemos bien a estos buenos católicos sudamericanos, su santidad, su culto a la mujer y su doble moralidad, como se ve en sus prósperas casas de tolerancia" ${ }^{44}$.

Para Ross, la conciencia moral no es un vaticinio en el cual hable la voz de Dios, de la naturaleza humana o de la razón, "la reacción espontánea de tipo instintivo a las cuestiones incorporadas en el ambiente en el cual el individuo ha sido educado, y que, por ello, refleja los juicios y los prejuicios del tiempo" ${ }^{45}$. Precisamente por este asunto, Ross concluye que las reacciones sancionatorias con respecto a la esfera de la vida sexual se justificarían si, y solamente si, se lograse demostrar que sirven para la protección de intereses merecedores de tutela.

El punto -se puede entrever- está en la brecha entre el sentimiento del pudor y la indignación moral: diríamos entre certeza sin verdad y verdad sin certeza. La línea de demarcación de la noción de 'daño a otros' está -contra la prolongación espantosa de las intolerancias- en la experiencia real y pragmática vivida por el individuo. "El pudor -así Ross- se encuentra ofendido por aquello a lo cual se asiste, mientras que la indignación moral puede des-

44 A. ROSS, “Omaggio a Fanny Hill”, en A. ROSS, Democrazia, potere e diritto, cit., p. 101. 45 Ibid. 
pertarse inclusive solo sabiendo de algo que está equivocadamente ocurriendo. La violación del pudor presupone una experiencia realmente visible (...) El pudor no puede, como es el caso del sentimiento moral, ser solicitado por el sólo conocimiento que algo ha sido realizado" 46 .

La línea divisoria entre la indignación moral y la ofensa al sentimiento de pudor no debe traspasarse nunca. Nos ofrece -dice Ross- un criterio decisivo en cuanto al tema de la publicación y difusión de escritos con contenido pornográfico. Es a la luz de estos argumentos que Ross, en Homenaje a Fanny Hill, no mostró reticencia alguna en apoyar la traducción danesa y la sucesiva publicación de la novela Memoirs of a Woman of Pleasure, un clásico de la literatura pornográfica inglesa escrito por John Cleland y publicado en 1749. Mejor conocida como Fanny Hill, la novela cuenta la historia erótica de una joven que se entrega con soltura a los placeres del cuerpo. La publicación en danés se inició en 1957 y luego fue detenida por la policía por violar las disposiciones penales sobre la publicación de actos obscenos. Tras un largo proceso judicial, en 1965, el Tribunal Supremo decidió autorizar su publicación, habiendo reconocido cierto valor literario a la novela ${ }^{47}$. El principio invocado por Ross a favor de su publicación fue la tolerancia, por lo que ningún acto debe prohibirse únicamente sobre la base de que otros se sientan ofendidos. "Y en virtud de este principio -así concluyó Ross con inevitable humor- exijo el derecho a ser blasfemo (...) y también a leer toda la literatura pornográfica que deseo" ${ }^{48}$.

Así que Ross le cerró las puertas a la posibilidad de imponer sanciones penales con respecto a los actos y comportamientos susceptibles de propiciar solo indignación moral (moralsk foragelse) y no respecto a comportamientos que puedan ofender al sentimiento del pudor (blufxerdighed): la posible viabilidad de la misma exposición a imágenes 'obscenas' (potencialmente perjudicial para el pudor, por razones de decencia pública) depende del contexto (lugar y forma $)^{49}$. No se puede evitar la exposición pública a imágenes pornográficas, observó Ross. Piénsese en las que aparecen en una pantalla o en un escaparate, por ejemplo. Por el contrario, puede ser evitado por completo el contenido 'obsceno' de un libro, desde el momento en que la lectura presu-

$46 \quad$ Ibid., p. 111.

47 Por una reconstrucción del asunto judicial ver: J. EVALD, Alf Ross- et liv, cit., p. 339.

48 A. ROSS, “Omaggio a Fanny Hill”, cit., p. 105.

49 Léase sobre este punto: M.E.J. NIELSEN, “Ross og ytringsfriheden”, en J.v.H. HOLTERMANN y J. RYBERG (eds), Alf Ross, Kritiske gensyn, Jurist og Økonomforbundets Forlag, Copenhague, 2006, pp. 127-149. 
pone y requiere una participación activa del lector que podrá, con el tiempo, advertir el carácter 'dudoso' del libro ${ }^{50}$.

Una vez más, Ross no traiciona el espíritu que mantiene unidos los bellos ensayos del volumen de 1974: el derecho no puede reducirse tanto al poder como a cualquier otro fenómeno social, y mucho menos a la moral. Para Ross, el derecho no es más que un instrumento de defensa y de expansión del individuo. El ejercicio de la razón, entre la libertad de expresión y la acción responsable, se concreta precisamente en la práctica de la democracia. Una vida entera, la de Ross, caracterizada por una enérgica aversión a los ensueños metafísicos y a las fugas hacia la fe, peligrosos a sus ojos, debido a que oscurecen la idea de la razón.

Demokrati, magt og ret se cierra con estas hermosas palabras: “ ¿La vida se vuelve insoportable sin el consuelo de la fe? No. La conciencia del gran vacío impregna la vida, con amarga dulzura, de la preciosidad por la cual ella sólo puede ser vivida una vez" ${ }^{51}$. Palabras más bellas no pudieron revestir su mensaje de iluminismo incondicional, un mensaje que Ross, en su incansable actividad como filósofo, jurista y comentarista social, defendió a capa y espada hasta los últimos días de su vida.

Alessandro Serpe Dipartimento di Scienze giuridiche e sociali Università degli Studi G. D'Annunzio di Chieti e Pescara Italia e-mail:alessandro.serpe@unich.it

50 Sobre el punto ver también, A. ROSS, "Blufærdighed og moralsk foragelse", Politiken, 1-11-1966, tambíen en I. FOIGHED, H. GAMMELTOFT-HANSEN y H. ZAHLE (eds), Alf Ross 1899-1999. Ret sam teknik, kumt og videnskab - og andre essays. Alf Ross 100 år, Jurist og Økonomforbundets Forlag, Copenhague, 1999, pp. 90-94.

51 A. ROSS, "Credo", en A. ROSS, Democrazia, potere e diritto, cit., p. 119. 